\title{
Abstract \\ Characteristics and limitations of electro-ocular recording
}

JOHN W. SENDERS, University of Toronto, Toronto, Canada M5S $1 A 4$

The genesis, the exodus, and the analysis of electro-ocular signals.

\section{REFERENCES}

Kris, C. Vision: Electro-oculography. In O. Glasser (Ed.), Medical physics. Chicago: Yearbook Publishers. 1960.

Gonshoor, A., \& Malcolm, R. The effect of changes in illumination level on electro-oculography. Aerospace Medicine, 1971, 41, 138-140.

Young L., \& Sheena, D. Survey of eye-movement recording techniques. Behavior Research Methods \& Instrumentation. 1975 , in press. 